\title{
THE PSYCHOLOGICAL DETERMINANTS CAUSING TENDENCY TO XENOPHOBIA AT STUDENTS OF HUMANITARIAN COLLEGES
}

\author{
Anna V. Litvinova, Konstantin Tarasov \\ Moscow City University of Psychology and Education (MCUPE), Moscow, Russia \\ E-mail: annaviktorovna@mail.ru, tarasovko@mgppu.ru
}

\begin{abstract}
Research analysis features of the educational environment of higher education institution and personal characteristics of students depending on the tendency to xenophobia. 50 students of humanitarian higher school settlements took part in the research. According to the criterion of "proximity - remoteness» in relation to the category «us - them» two groups of students were singled out - with more and with less expressed tendency to xenophobia's manifestation. As a result it was established that the tendency for xenophobia depended on some external determinants like culture levels of fellow students, personal and psychological characteristics of teachers, and on such internal determinant as traditional cultural values (interesting work, sense of duty, irreconcilability) and application of socially approved ways of a goal-setting.
\end{abstract}

Key words: psychological determinants, psychological safety of the educational environment xenophobia, xenophobia mechanisms.

\section{Introduction}

\section{Problem of the Research}

In a modern situation of transition from post-industrial society to the society full of risks and threats, importance of safety as a global value increasingly raises. It is connected with social and economic living conditions, growth of social tension and discrepancy of the interethnic relations, increase in the migratory inflow, elevating the risk of xenophobia manifestations. Russian researchers (Guseva, 2004; Popova, 2007; Skripkina, 2010) note that Russian youths display ethnic, social and personal intolerance to certain ethnic and social groups of people. However, it is impossible to put up a democratic state, to create a high-grade civil society without tolerant attitudes to other social or ethnic groups. In this regard the study of psychological determinants of tendency to xenophobia attains special urgency. Research of this problem is carried out in logic of a functional approach (Shabelnikov, 2004) opening that the base conflict "own-another" is a source of development of society and the personality. At a stage of development of patrimonial society and personality formation at the corresponding stage of ontogenesis this conflict is shown as the form of external aggression in relation to surrounding vital space "own" and "another". Further, the conflict of interiorisation in an inner world of base feelings and representations acts as a condition of formation of independence both social, and the individual subject in the organization of a new image of activity on the basis of self-aggression and reflection mechanisms. These provisions became the basis of studying of specifics social and personal determinant, defining manifestation of the tendency to xenophobia by students of humanitarian colleges. 
The theoretical approaches to study of social and psychological features of xenophobia manifestations were regarded in several studies of national and foreign psychologists (Derkach, 2007; Krayg, 2003; Petrovskaya, 2007; Pochebut, 2000; Semenov \& Stefanenko, 2008; Soldatova, 2006; etc.), the ways of preventions of xenophobia and formation of ethnic tolerance were discussed in the following works (Asmolov, 2007; Andreeva, 1996; Grishpun, 2007; Tishkov, 2010; Shlyagina, 2011 etc.). Xenophobia is considered to be a negative, emotionally charged, irrational by its nature attitude of a subject to certain communities and their representatives - "aliens", "others", «not us», caused by the fear of loss of the resources, identity, space (Yurasova, 2008). Xenophobic attitudes and stereotypes are formed in the course of socialization of an individual and his/her interpersonal communication and they are reproduced through social transmission from one generation to another. The basis for development of tolerance at individual and group levels is provided by immunity to the socio-cultural and ethnic distinctions which is formed in the course of socialization and an interiorization of the norms of cultural diversity fixed in public consciousness, individual distinctions and the main universal values.

Xenophobia is one of the most important versions of intolerant relations to others, "aliens" (Soldatova \& Makarchuk, 2006), it is a fear and rejection of any groups which are perceived as "strangers" (ethnic, religious, social) (Yurasova, 2008). Sources of xenophobia root in public and in individual consciousness, and people are inclined to perceive and estimate vital circumstances on the basis of traditions, values of their own social group which represents itself as "us". V. Shabelnikov (2004, p. 481), facing the problem of socio-cultural determination of personality development, states that the history of any society includes the expansion of new forms of culture with a simultaneous preservation in its deep layers the former mechanisms of determining motives and identity qualities. In the course of transition from traditional to reflective culture the base intergeneric conflict «good ours - bad strangers» is appropriated by the individual, transferred to his inner world and becomes a power source of reorganization of activity and activity of the personality. Social revolutions and personal crises promote disappointment of people in determining myths, values, ideals, relieve them of unconscious stereotypes of external management of activity and behavior. Acquiring and reproducing reflective culture of people becomes the mature personality, will organize constructive interaction with representatives of ethnic and social groups.

The ontogenetic study of the alternative «us - them» carried out by Russian researchers (Soldatova \& Makarchuk, 2006) showed that expansion of the category "us" begins at preschool age and proceeds throughout school age. At preschool age a child is the obedient carrier of the prescribed ways and schemes of activity, but already at teenage a child displays an active denial of social culture, rejection of difficult levels of activity and group opposition to difficulties of the surroundings. Thus beginning with middle school age a child attributes to «us» the maximum quantity of objects, while the group "them" tends to be significantly reduced.

At the senior school age alongside with ethnic identity there starts the formation of the social categorization representing child's identification with his/her group and the acceptance of the group norms with a simultaneous opposition to other groups. The category «us» in a higher school gains an "elitist" character, the teenager actively looks for "his/her" significant people and "his/her" social groups. Due to maximalism typical for teenagers, "us" turns into an unequivocally positive category, "them" - into a negative and partially ambivalent one (Soldatova \& Makarchuk, 2006) The higher school students is the least tolerant and most inclined to xenophobic displays part of our society (Soldatova \& Makarchuk, 2006). The middle and senior school age is a specific period in a teenager's development when the emotional imbalance between the leading categories defining a social order in the world strengthen significantly and the alternative «us - them» alongside with the behavioral strategies in interacting with "others" is being developed, giving way to xenophobic thinking. Middle and senior teenage is the boundary which sets rigid alternative «us - them» and xenophobic attitudes.

Skripkina (2010) considers that university students estimate more adequately than higher school students the state of events in Russian society and are more critical in their estimations, more so, the level of their social trust is more realistic, than that of schoolchildren. 
However, this tendency is not observed in young people who do not have the university education: this group is intolerant enough and displays a high level of xenophobia. University students also possess the expressed xenophobic installations and show intolerance in relation to other ethnic, national, racial groups and to representatives of other religions (on the average 25, $6 \%$ of the interrogated students). Students from the republics with less homogeneous national structure display higher tolerance to representatives of other national, ethnic and racial identity.

Maintenance of a certain balance between negative environmental impacts on a person and his/her stability, assumes the availability of psychological safety as a necessary condition of mental safety, ability to overcome such influences with one's own resources or with the help of the protective factors of the environment. Psychological safety of a personality and its environment are inseparable from each other and represent a model of a sustainable development and a productive functioning of a person in interaction with the environment (Baeva, 2002). In this regard, the study of factors of psychological safety of the educational environment as external determinants of xenophobia manifestations by students of higher education institutions becomes an acute problem.

In our research the internal determinant of xenophobia are exemplified by such individual psychological features as xenophobic attitudes, value orientations, goal-setting. Dozortseva and Malantseva (2010) established that xenophobic attitudes are closely connected with semantic and moral spheres of a personality, and they may be connected with certain individual and psychological features elevating the risk of behavioral manifestations of xenophobia. The personality relations to the outer world, surrounding people and to self are determined by the system of value orientations which plays a role of «philosophy of life». The work studies goals-values and means - values which refer to traditional values and the values of self-realization providing an inclusiveness of an individual in various socio-cultural situations. The problem of choice and life perspective shaping is especially acute in youths. It is extremely important for young people entering the «adult life» to choose their own way, and to have wishes and goals to materialize them in the process of arranging their life span activity.

\section{Methodology of Research}

\section{General Bases of Research}

We assume that tendency to xenophobia is caused by external (factors of psychological safety of the educational environment), and internal (attitudes, value orientations, goal-settings) determinants. The purpose of the study is to examine external and internal factors determining the relations of students to representatives of ethnic and social groups.

\section{Sample of the Research}

For realization our study, it was carried out empirical research, where 50 students from humanitarian educational settlements and non-need families (middle age - 19, 8 years) took part. The choice of this age group is linked with the fact that it is time of personality socialization, when individual's civic and professional responsibilities emerge, and norms and rules of group behavior are being shaped.

\section{Instruments and Procedures}

The projective technique "Street" (Gulevich, 2007, p. 318) adapted under research problems was applied to define the preference of a referent group to categories «us - them». The form with the image of houses on the street and the list of representatives of various ethnic, social groups was provided to examinees. The instruction was as follows: «Imagine, that families belonging to different groups live on the same street with you. First, define, where you live, then find "the place" for the others». On the basis of the criterion of "nearness" and "farness» to "others" two groups were singled out.1 group included the examinees who mainly settled themselves near «us » 
that can testify to more expressed tendency to xenophobia. The 2 nd group was made of examinees who settled themselves near the representatives of various groups, which assumed less expressed tendency to xenophobia.

Research of external determinants was carried out with the help of the «Scale of factors of psychological safety of the educational environment». The instruction was as follows: «Estimate the risk factors influencing the safety of the educational environment of a higher education institution» Answers were estimated on a scale: 1-very low, 2-low, 3-average, 4-high, 5-very high. For internal determinants' research the questionnaire was applied to clarify the respondents 'relations to people of other nationalities, as well as the technique of «Value orientations» and "Goal-orientation". The questionnaire of detection of tendency to (Yurasova, 2008) xenophobia is directed on clarification of the relation of the respondent to persons of other nationalities and to the own nation. On offered approvals by the examinee it was necessary to choose one of three versions of the answer: "yes", "no", I "do not know".

The technique of «Value orientations» by Rockich was applied to identify the domineering goal-values and means-values. We chose this technique because the system of valuable orientations acts as a basis of «life philosophy», defines the substantial part of an orientation of a personality, its relation to the world, surrounding people and to itself. Instructions were as follows: «Please rank value from the list A and the list B in the order of the importance for you, as principles by which you are guided in your life. To the most significant value the 1st rank is appropriated, to the least important - the 18th».

The technique of goal-setting study (Litvinova, 2011) was applied to find out the features of putting and achieving the goals of life sustaining activity. Stimulus material included 24 pairs of statements which allowed carrying out the comparison of degree of expressiveness of some statements which were estimated in points from 0 to 3 . Instructions for examinees were as follows: «Pairs of statements are offered to you. Your task is to choose one or the other statement and to estimate it: « it is rather not, than yes» - 1 point, «rather yes, than no» - 2 points, "yes" - 3 points. If in your opinion both statements are equally true -0 points. Points for each examinee were calculated with the help of a specially designed scale. The results helped to draw a conclusion about the process of goal-setting.

\section{Data Analysis}

The statistical analysis of data was carried out by means of the correlation analysis with use of the factor of Pearson (a software package of SPSS 17.0.).

\section{Results of the Research}

Data obtained with the help of the technique "Street" and criterion of "proximity" made it possible to singled out two groups of examinees: the group with a higher tendency for xenophobia ( $1^{\text {st }}$ group) and the group with a lower tendency to xenophobia (the 2 nd group). 1 group included $44,83 \%$ of students, the second group $-55,17 \%$. To establish the links between the tendency to xenophobia and preferences of referent groups the correlation analysis was carried out. Tendency to xenophobia displays correlation with the immediate environment - «us ». The received results are presented in tab. 1 .

Table 1. Representation of referent groups in accordance with students' tendency to xenophobia.

\begin{tabular}{|c|c|c|c|}
\hline Group & Parameters & Coefficient of correlation & Level of significance \\
\hline 1 & Classmate & 0.57 & 0.01 \\
\hline 1 & Fellow students & 0.36 & 0.05 \\
\hline 2 & Members of the neighbouring countries & 0.30 & 0.05 \\
\hline
\end{tabular}




\begin{tabular}{|c|c|c|c|}
\hline Group & Parameters & Coefficient of correlation & Level of significance \\
\hline 2 & Africans & 0.40 & 0.01 \\
\hline 2 & Jews & 0.36 & 0.05 \\
\hline 2 & Labor migrants & 0.30 & 0.05 \\
\hline
\end{tabular}

Group mates and fellow students appear to be representatives of the immediate environment for the students of the $1^{\text {st }}$ group. Their commitment to the immediate environment complicates development of ethnic identity and promotes to ethnocentrism and xenophobia formation. Students of the 2-nd group in contrast display commitment to representatives of various ethnic and social groups, and representatives of the neighboring countries, Africans, Jews, labor migrants are referential for them.

The following stage of investigation was aimed at establishment of interrelations between the tendency to xenophobia and factors of psychological safety of the educational environment, which were regarded as external determinant of personality development.

Table 2. Expressiveness of external a determinant as depending on students' tendency to xenophobia.

\begin{tabular}{clcc}
\hline Group & \multicolumn{1}{c}{$\begin{array}{c}\text { Factors of psychological safety } \\
\text { of the educational environment }\end{array}$} & $\begin{array}{c}\text { Coefficient of } \\
\text { correlation }\end{array}$ & Level of significance \\
\hline 1 & Level of culture of classmates & 0.31 & 0.05 \\
1 & Personal and psychological characteristics of teachers & 0.30 & 0.05 \\
2 & Bias of opinions of teachers about students & 0.30 & 0.05 \\
2 & Suppression in student's collective & 0.35 & 0.05 \\
2 & Tendency to destructive behavior & 0.36 & 0.05 \\
2 & Violations of mental and physical health & 0.45 & 0.01 \\
2 & Difficulties of contact with classmates & 0.36 & 0.05 \\
\hline
\end{tabular}

The carried-out correlation analysis allowed finding out that culture levels of group mates alongside with personal and psychological characteristics of teachers serve as external determinants in the $1^{\text {st }}$ group. The received results make it possible to conclude that certain characteristics of representatives of the immediate environment can even increase tendency to xenophobia manifestation in students of this group. Thus it can be argued that some characteristics of the nearest environment may raise tendency to xenophobia in students of this group in case of difference in understanding of "us".

Let's note that in group 2 external determinants are more differentiated and their range is wider. Thus they include the teachers' biased opinions about students, suppression in student's group relations, difficulty in contacts with group mates, tendency to destructive behavior, mental and physical health disorders. Mentioned above factors of psychological safety of the educational environment do not only particularize tension in relations with surrounding people, but also help students of this group to find acceptable strategies of problem solving. 


\section{Table 3. Expressiveness internal a determinant depending on tendency of} students to xenophobia.

\begin{tabular}{|c|c|c|c|}
\hline Group & $\begin{array}{l}\text { Factors of psychological safety of the educational } \\
\text { environment }\end{array}$ & $\begin{array}{l}\text { Coefficient of } \\
\text { correlation }\end{array}$ & Level of significance \\
\hline \multicolumn{4}{|c|}{ Installations of xenophobia } \\
\hline 2 & Special prohibitive measures aren't necessary & 0.31 & 0.05 \\
\hline \multicolumn{4}{|c|}{ Purposes values } \\
\hline 1 & Interesting work & 0.34 & 0.05 \\
\hline 2 & Love & 0.30 & 0.05 \\
\hline 2 & Knowledge & 0.32 & 0.05 \\
\hline 2 & Happy family life & 0.45 & 0.01 \\
\hline \multicolumn{4}{|c|}{ Means values } \\
\hline & Sense of duty & 0.37 & 0.05 \\
\hline 1 & Irreconcilability & 0.30 & 0.05 \\
\hline 2 & Accuracy & 0.32 & 0.05 \\
\hline 2 & Cheerfulness & 0.43 & 0.01 \\
\hline \multicolumn{4}{|c|}{ Goal-setting } \\
\hline 1 & $\begin{array}{l}\text { I apply socially approved ways of achievement of the } \\
\text { purpose }\end{array}$ & 0.30 & 0.05 \\
\hline 2 & I estimate the result by my own criterion & 0.37 & 0.05 \\
\hline
\end{tabular}

Let's analyze the internal determinants which define the personal relations of students and either promote or brake their interactions with surrounding people. In group 1 the traditional goalvalues like «interesting work», "means- values", "sense of duty", "irreconcilability" are expressed. It's interesting that the distinguishing feature of students in this group is an application of socially approved ways of goal-setting, which discloses their striving to rely on established "landmarks" and social expectations relating to «us». Students from group 2 significantly prevail traditional the purpose - value «happy family life» both means value "accuracy" and the purposes - values of development "love", the "knowledge" promoting more differentiated acceptance of people around. Students from group 2 are more independent in a goal-setting, they created system of own criteria of an assessment of results of actions.

\section{Discussion}

It should be noted that students from group 2 consider not necessary special prohibitive measures for the relation to persons of other nationality for conflict prevention. Unlike with $1^{\text {st }}$ group, students from group 2 significantly prevail not only traditional values, but also the purposes - the values of development directed on more informative and confidential relation to surrounding reality and people. If students from group 1 are guided in the organization of a goal-setting on people around and their actions are operated from the outside, students from group 2 show big independence in a goal-setting, they estimate the reached results of actions on the basis of own criteria.

Summing up, it should be noted that earlier the problem of xenophobia wasn't considered in logic of the functional approach defining the conflict "own and others"” as the basis of development of society and the personality.

\section{Conclusion}

As a result of the carried-out research the data opening specifics of social and personal determinant of tendency to xenophobia at students of humanitarian colleges were obtained.

The students, who were more inclined to xenophobia, differ aspiration to cooperate with «owns». 
They divide traditional values and rely on ways of a goal-setting socially approved in the immediate environment that allows to draw a conclusion on an inclusiveness them in a sociocultural situation with rigid structure of the traditional society, assuming manifestation of external aggression.

The students who were less inclined to xenophobia are directed on interaction with different social and ethnic groups. Informative interest to them is connected with values of development, constructive installations, reflective relation to positive and negative sides of interaction with people around. Students of this group differ more created goal-setting, existence of system of criteria of an assessment of realization of independently goals. All this can serve as the proof of an inclusiveness of students in a sociocultural situation with flexible structure of democratic society on the basis of self-aggression and reflection manifestation in the interaction organization with people around.

The received results will allow to predict formation of tendency to xenophobia and to create conditions for development of the mature personality capable structurally to cooperate with people around. They can be used at psychological consultation of subjects of the educational environment of higher education institution, for the purpose of xenophobia prevention. Studying of tendency to xenophobia at students of technical colleges as functions of activity mastered by it are more conservative that assumes structure of more traditional values necessary for its realization is perspective and in a certain measure interferes with an interiorization of the base conflict.

\section{References}

Baeva, I. A. (2009). Psychological safety in education. Saint-Petersburg: Ekon-Inform.

Dozortseva, E. G., \& Malantseva, O. D. (2010). Psychological Characteristics of Adolescents prone to xenophobia. Psychological Science and Education, 2, 44-53.

Gulevich, O. A. (2007). Psychology of the intergroup relations. Moscow: MPSI

Guseva, O. U. (2004). Ethnic identity in a situation of intercultural interaction and in the conditions of the monoetnic environment. Dissertation of the candidate of psychological sciences. Moscow.

Kagan, V. (2004). Homo Xenophobicus: psychology personal and others'. Century of Tolerance, 7, 28-42.

Litvinova, A. V. (2011). Influence of psychological safety of higher education institution on statement goals by students. In Psychological problems of safety in education. Moscow State University of Psychology and Education, p. 111-115.

Shabelnikov, V. K. (2004). Functional psychology. Moscow: Academic project.

Skripkina, T. P. (2010) Installations of tolerant consciousness, trust and xenophobia at the youth living in the southern Russian region. Social Psychology and Society, 1, 136-151.

Soldatova, G. U., Makarchuk, A. V. (2006). Whether there can be another friend? Training on xenophobia prevention. Moscow: Genezis.

Stefanenko, T. G. (2003). Ethnopsychology. Moscow: Aspect Press.

Yurasova, E. N. (2008). Psychological features of the persons inclined to extremism, terrorism and xenophobia. Legal Psychology, 4, 27-35.

Advised by Julia Lakhvich, Belarusian State University, Republic of Belarus

Received: April 22, 2012

Accepted: June 25, 2012

\begin{tabular}{cl}
\hline Anna V. Litvinova & $\begin{array}{l}\text { PhD, Associate Professor, Senior Researcher, Moscow City University of Psychology } \\
\text { and Education (MCUPE), Moscow, Russia. } \\
\text { E-mail: annaviktorovna@mail.ru }\end{array}$ \\
\hline Konstantin Tarasov & $\begin{array}{l}\text { Graduate Student of Moscow State University of Psychology and Education, Pobedy } \\
\text { square, b. 2/1, apt. 83, Moscow, Russia. } \\
\text { E-mail: tarasovko@mgpu.ru }\end{array}$ \\
\hline
\end{tabular}

